\title{
Source distribution of neuromagnetic slow wave activity in schizophrenic and depressive patients
}

\author{
Christian Wienbruch, Stephan Moratti, Thomas Elbert, Ulrike Vogel, Thorsten Fehr, \\ Johanna Kissler, August Schiller, Brigitte Rockstroh* \\ Department of Psychology, University of Konstanz and Center for Psychiatry Reichenau, Konstanz 78457, Gernany
}

\begin{abstract}
..... Objective: Focal slow waves in the delta-and theta frequency fange frequently appear in psychopathological conditions. Düe to their focal nature they can be localized by dipole modeling. We previously reported regional clustering of slow waves in temporal and parietal cortex of schizophrenic patients whereas such activity is largely absent in normals. Here we examine, to what extent distribution of slow wave generators differentiates schizophrenic from depressive syridromes.

Methods: The regional densities of generators of focal slow waves were determined during resting conditions in patients with DSM-IV diagnoses of schizophrenia $(N=25)$ and depression $(N=27)$ and in 18 healthy controls.

Results: Schizophrenic patients demonstrated accentuated temporal and parietal delta and theta dipole clustering, when compared to both the control and the depressive sample. In contrast, depressive patients had reduced frontal and prefrontal delta and theta dipole density relative to both schizophrenics and controls. This pattern was not related to age. Men generally displayed somewhat higher slow wave activity than women. For the areas of most pronounced slow wave deviances activity within each group was related to symptom scores: higher left-temporal slow wave activity was associated with hallucinations in schizophrenics, suppression of left-prefrontal slow wave activity correlated with depression scores.

Conclusions: Results suggest that slow wave distribution may assist in differentially diagnosing psychopathological conditions.
\end{abstract}

Keywords: Schizophrenia; Depression; Magnetoencephalography; Delta; Theta; Dipole density

\section{Introduction}

Large amplitude and low frequency activity in the electroencephalogram (EEG), e.g. in the delta or theta frequency range, have mainly attracted neurologists' interest. If prominent during the waking state, slow waves generated in a circumscribed brain region often appear in the vicinity of a structural lesion like cerebral infarct, contusion, local infection, tumor, epileptic foci or subdural hematoma (Tanaka et al., 1998; De Jongh et al., 2001, 2002; Vieth et al., 1996, 1998, 2000; Möller et al., 2002; Gallen et al., 1992, 1993; Fernandez-Bouzas et al., 1999). Being explained by metabolic or blood flow changes consequent. upon the structural lesion, focal slow waves have been

\footnotetext{
* Corresponding author. Department of Psychology, University of Konstanz, P.O. Box D23, D-78457 Konstanz, Germany. Tel.: + 49-7531882085: fax: + 49-7531-882891.

E-mail address: Brigitte.Rockstroh@uni-konstanz.de (B. Rockstroh).
}

attributed to pathological or 'dysfunctional' neural tissue (Niedermeyer and Lopes da Silva, 1987; Lewine and Orrison, 1995). Similar to the interpretation of slow oscillatory rhythms during sleep stages as deafferentation of the cortex due to thalamic hyperpolarisation (Steriade, 1997), abnormal focal slow wave activity in the waking. state might indicate functional deafferentation in the sense of reduced information processing and impaired neuronil network communication in affected brain regions (Gloor et al., 1977; Amzica and Steriade, 1997).

The well-established neurological view of focal slow waves as indicative for dysfunctional brain regions suggested to explore this measure also to uncover deficits in brain functioning in various psychopathological conditions. Indeed, augmented activity in lower EEG-frequency bands had been reported, for instance, for schizophrenia patients (Elbert et al., 1992; Clementz et al. 1997: Sponheim et al., 2000; Winterer and Hermann. 1995; 
Harris et al.; 1999, 2001; Koshino et al., 1993), dementia (Buchan et al., 1997, Dierks et al., 2000; Berenđse et al., 2000; Franciotti et al., 2002), and even posttraumatic stress disorder (PTSD; Teicher et al., 2002; Begic et al., 2001).

This was complemented by mapping slow wave generators in the magnetoencephalogram (MEG), which in schizophrenic patients disclosed a clustering in temporal and parietal regions (association cortices). (Canive et al., 1998; Fehr et al., 2003; Sperling et al., 2002) and in anterior areas (Pascual-Marquis et al., 1999).

In depression, EEG-delta/theta augmentation (Knott and Lapierte, 1987; Llinas et al., 1999; Volf and Passynkova, 2002; Nystrom et al., 1986), reduction (Brenner et al., 1986; Knott et al., 2000), and no change from controls (Visser et al., 1985; Pollock and Schneider, 1990) have been reported. Differences between studies may have resulted from age differences, given that higher age may vary with increased risk for cognitive impairment or dementia. Dahabra et al. (1998) found a correlation of (enhanced) slow wave activity and cognitive impairment in (older) depressive patients irrespectively of duration of illness, structural abnormalities and clinical remission. Pozzi et al. (1995) controlled for the influence of age and dementia by comparing depressive patients with and without dementia; they found an increase of posterior delta and theta activity (relative to controls) in demented depressives but a reduction in non-demented depressives. Moreover, increased slow wave activity - mainly in prefrontal sites-was reported after treatment with ECT (Heikman et al:, 2001; Sperling et al:, 2000; Sackeim et al., 1996; Luber et al., 2000) or medication (Landolt and Gillin, 2002; Schulz et al., 2000) ${ }^{1}$.

Additional support for the functional significance of slow wave activity was derived from relationships with symptomatology. Already in 1979, Stevens et al. observed characteristic EEG spectra in schizophrenic patients during periods of hallucinations. More recently, Lewine et al. (2002) found enhanced left-temporal MEG-theta activity in schizophrenic patients with hallucinatory symptoms, and Sperling et al. (2002) reported a positive correlation between focal magnetic delta concentration and positive symptoms. Symptom improvement with neuroleptic treatment changed slow wave activity in schizophrenia (Saletu et al., 1994; Begic et al., 2000).

Evidence from imaging studies indicating structural and functional abnormalities in temporal and frontal, lefthemispheric regions in schizophrenic patients (Bogerts, 1997; Shenton et al., 2001; Jones, 1997), as well as of the finding of a relationship between reduced hippocampus volume and increased theta activity in PTSD (Begic et al.,

\footnotetext{
As the present study concentrates on slow wave activity, the extended literature on deviant hemispheric asymmetry in affective disorders, which "as established mainly for EEG alpha activity (Henriques and Davidson, 1991; Knott et al., 2001; Allen et al., 1993; Debener et al., 2000; Nystrom ci at.. 1986). but also from metabolic findings (Baxter et al., 1989; Bench et al.; 1992). will not be considered.
}

2001; Teicher et al., 2002) further strengthens the hypothesis that excessive focal slow wave activity is associated with focal dysfunction.

Any focally generated source can well be modeled by means of an equivalent current dipole (ECD). In fact, the quality with which the ECD model fits to a particular - magnetic source configuration can be used as a filter to extract focally generated slow waves from more widely distributed sources (Elbert, 1998). This is the case for MEG activity, as the MEG is largely blind for radial sources that typically result when large cortical areas spanning across gyri and sulci become active.

The present study aimed at further exploring the significance of focal slow wave activity by comparing groups of patients with diagnoses of schizophrenia and of affective disorders to normal controls. It was also explored whether a diagnosis-specific topographical pattern of slow wave activity might be related to measures of diagnosisspecific symptoms. The data reported here result from : larger project on the diagnostic usefulness of focal slow wave mapping. Data of the schizophrenic sample have been reported in part by Fehr et al. (2003). As there were no differences between the original 16 and the presently added 13 schizophrenic patients in the outcome measures, they -. were pooled in the present analysis.

\section{Subjects and methods}

\subsection{Subjects}

Twenty-nine inpatients (12 females, $31.6 \pm 8.9$ years) with the DSM-IV diagnosis of a schizophrenic disorder (18 paranoid-hallucinatory, 11 disorganized type) and 29 inpatients (19 females, $45.1 \pm 9.4$ years) with the DSMIV diagnosis of affective disorder (14 patients with major depressive episode, 8 patients with recurrent episodes, 6 patients with mood disorders related to PTSD, one patien. with bipolar affective disorder currently fulfilling criteria for a major depressive episode) were investigated. Results were compared to those from 18 healthy subjects (two females, $33.1 \pm 13.1$ years). Regular drug tests ascertained that patients did not.use recreational drugs other than nicotine during their inpatient treatment. In line with frequent psychiatric observation, diagnostic interviews upon admission verified that most of the schizophrenic patient's had used cannabis or alcohol occasionally or frequently, whereas the abuse of heroin or cocaine was reported only by 3 patients; in the depressive sample, occasional or regular alcohol use was reported by more than half of the patients. Control subjects did not report any history of psychiatric illness or drug abuse and were not under current medication.

In all subjects, handedness was assessed by a modified version of the Edinburgh Handedness Questionnaire (Oldfield, 1971), asking subjects to demonstrate hand use on 
various actions (like using a broom, brushing teeth, writing, etc.). Five schizophrenic and two depressives patients proved to be left-handed, while all controls were determined as right-handed according to the test. As effects of handedness on hemispheric asymmetry of responses may be expected, all left handers were excluded from data analyses. Analyses reported below include 24 right-handed schizophrenic (12 females, $31.8 \pm 9.2$ years) and 27 depressive (18 females, $45.9 \pm 9.1$ years) patients.

Diagnoses were given by the psychiatrist or psychologist in charge on the basis of DSM-IV criteria (German version of the Structured Clinical Interview for DSM; Wittchen et al., 1997, or Present State Examination, PSE, Wing, 1982). On the day of testing, both therapist and patient had confirmed that the status of the patient had improved sufficiently to allow participation in the MEG recording session. When estimated by their inpatient status, none of the patients was in a remitted state; when estimated by psychopathology rating scales (Beck depression inventory, BDI, or positive and negative symptom scale, PANSS, Kay et al., 1987), improvement was indicated for 5 depressive patients (BDL below .18) and 10 of the schizophrenic. patients (average PANSS-P and PANSS-N score below 17).

In each of the 24 schizophrenic patients, the psychopathological status was assessed on the day of the experimental investigation by the psychologist/psychiatrist in charge by means of the PANSS (average scores PANSSP: $16.7 \pm 4.9$, range $10-26$; PANSS-N: $20.5 \pm 6.7$, range 9-33; PANSS-G: $37.8 \pm 12.0$, range $25-87$ ). Eighteen patients were under neuroleptic medication at the time of the assessment (11 receiving typical, 6 atypical neuroleptic drugs); the average daily dosage being $129.7 \pm 162.4 \mathrm{mg}$ Chlorpromazine equivalents. In the 27 patients with affective disorders, the severity of depressive symptoms was established with the BDI (mean $22.3 \pm 14.1$, range $1-57$ ) on the day of the experiment. Twenty-one patients were under current medication receiving tricyclic antidepressant $(N=3)$, selective serotonin reuptake inhibitors $(N=11)$, neuroleptics $(N=3)$, or, other new atypical antidepressants (like Selective Noradrenaline Reuptake Inhibitors, $N=2$ ).

Prior to the experimental session all subjects were familiarized with the recording environment, informed about the procedure and gave written consent to participate in the experiment. Participants were paid the equivalent of about US\$10.

\subsection{Data collection}

Using a 148-channel whole-head neuromagnetometer MAGNES $^{\text {Ta }} 2500 \mathrm{WH}$, 4D Neuroimaging, San Diego, USA) the MEG was measured during a 5 min resting period. Subjects were asked to relax but stay awake and not to engage in any specific mental activity. MEG recordings were obtained in a supine position. Subjects were asked to fixate a colored mark on the ceiling of the magnetically shielded room throughout the recording in order to avoid eye- and head-movement. A video camera installed inside the magnetically shielded room allowed monitoring the subject's behavior and compliance at any time throughout the experiment.

The patients index points and head shape were digitized with a Polhemus 3 Space ${ }^{\circledR}$ Fasttrack prior to each measurement. The subject's head position relative to the pickup coils of the sensor was estimated before and after each measurement. MEG was recorded with a sampling rate of $678.17 \mathrm{~Hz}$, using a real band-pass filter of $0.1-200 \mathrm{~Hz}$. For artifact control, eye-movements (EOG) were recorded from 4 electrodes attached to the left and right outer canthus and above and below the right eye; the electrocardiogram (ECG) was monitored via electrodes attached to the right collarbone and the lowest left rib using a Synamps amplifier (NEUROSCAN ${ }^{\circledR}$ ).

\subsection{Data reduction and analysis}

Data were decimated by a factor of 16 (antialias filters. -were applied automatically in the same processing step) and digitally filtered separately for delta $(1.5-4.0 \mathrm{~Hz})$ and theta $(4.0-8.0 \mathrm{~Hz})$ frequency bands using a digital band-pass filter (Butterworth filter). Artifact-free time segments were determined by visual inspection. Single ECDs were fitted. for each time point in the selected artifact-free segments. Five standard non-overlapping channel groups (left, right, center, anterior, posterior) were chosen for dipole modeling: A homogeneous sphere, which fits best in a least square sense the digitized patient's headshape below the selected sensors, served as a model for the volume conductor.

Only dipole fit solutions at time points with a root mean. square $100 \mathrm{fT}<\left(\mathrm{RMS}=\left(\sqrt{ }\left(\ln n \sum\left(x_{\mathrm{i}}\right)^{2}\right)\right)\right)<300 \mathrm{fT}$ and with a goodness of fit (GOF) greater than 0.90 were accepted for further analysis. These restrictions should ensure that neither artifacts nor small amplitude biological noise would affect the results, and that only dipolar fields that were generated by focal sources were analyzed. Since artifact-free epochs varied in length, the percentage of dipoles per second in a particular area was submitted to the statistical analyses.

Since individual anatomical information was not avail:able, the source space was divided into 10 subvolumes; which correspond to left- and right-prefrontal, frontal; temporal, parietal and occipital cortices of a standard brain The dipole densities show a log normal distribution and were consequently transformed to a normal distribution before scores were entered into further statistical analysis. Differences in the pattern of dipole densities between: conditions and groups were evaluated separately for the delta and theta frequency band by analyses of variance with the between-subjects factor GROUP and the within-subjects factors AREA (comparing prefrontal, frontal, temporal, and occipital dipole densities), and HEMISPHERE (comparing the left- and right-hemispheric areas). 


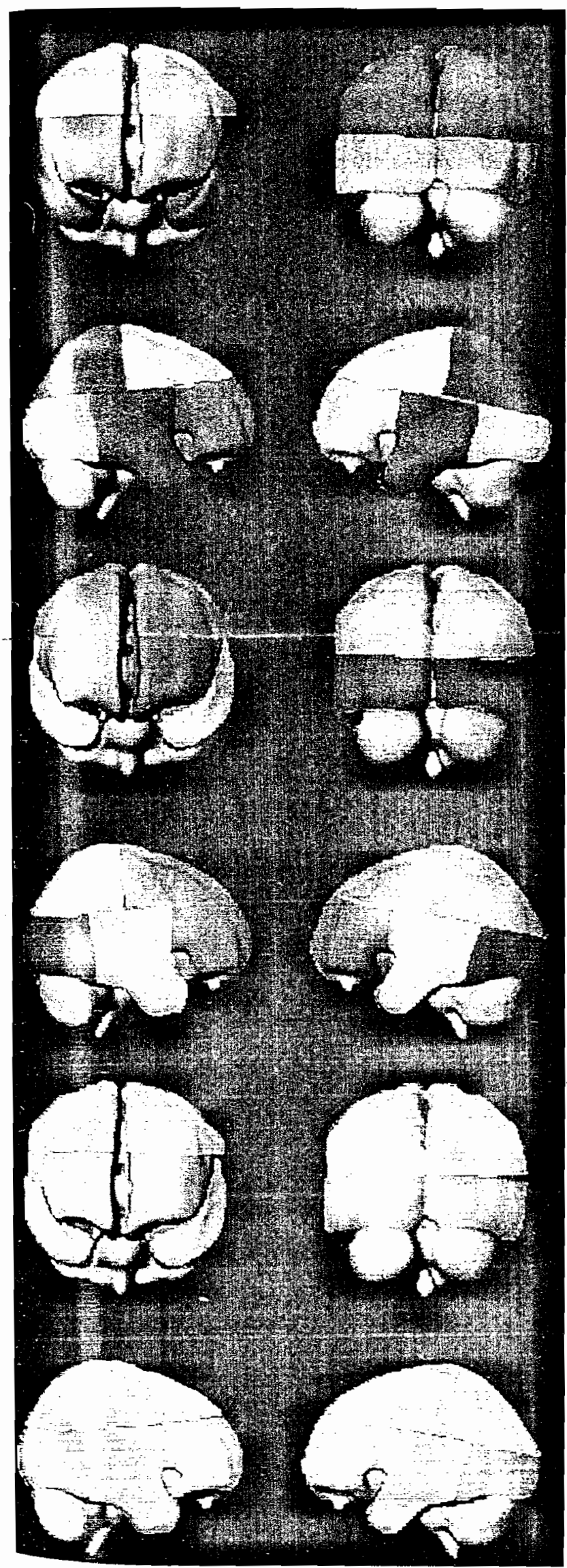

As consistent with the clinical reality, age and gender differed between groups (see above), possible effects of these variables on the distribution of delta dipole density were evaluated by means of an analysis of covariance with age as covariate, and separate ANOVAs with male and female subjects. For interactions with degrees of freedom larger than 1 , the df were corrected using the GreenhouseGeisser procedure to account for possible violations of the sphericity assumption. Interactions were verified by posthoc Scheffé or $t$ tests. Exploratory analyses examined a possible relationship between psychopathology and slow wave activity. As strong correlations between levels of measurement as different as symptom scores and slow wave generators seem unlikely, correlations were confined to the area of particularly prominent delta dipole concentration and prominent symptom scores of each group (depression measured by the BDI, hallucination and paranoia scores of the PANSS-P). The Holm correction factor was applied to account for multiple testing (Holm, 1979).

\section{Results}

Groups differed in the pattern of focal delta dipole density. Schizophrenic patients exhibited significantly more - pronounced temporal and parietal slow wave activity than the two other groups. In contrast depressive patients produced significantly less prefrontal slow wave activity than the two other groups (see Fig. 1; for the ANCOVA with age as covariate GROUP $\times \operatorname{AREA}(F(8,256)=3.10$, $\epsilon=0.72, p<0.01$; main effect GROUP, $F(2,64)=15.56$, $\ddot{p}<0.001$ ). Posthoc Seheffé tests confirmed significantly smaller percentage of delta dipoles in depressives than in schizophrenics in all areas $(p<0.0001)$, while differences between depressives and controls reached significance only in prefrontal $(p<0.0001)$ and frontal $(p<0.02)$ regions. Higher delta dipole density in schizophrenics than in controls was verified for the temporal $(p<0.05)$ and the parietal area $(p<0.02)$. (Considering male subjects $(12$ schizophrenics, 9 depressives, 16 controls) and female subjects (12 schizophrenics, 18 depressives, two controls) in separate ANOVAs confirmed the GROUP effect for each gender subsample (for men, $F(2,36)=9.14, p<0.01$; for women, $F(2,26)=13.00, p<0.01)$; posthoc $t$ tests, too, confirmed the significant group differences for male

Fig. 1. Distribution of dipole density in the delta band in schizophrenics (a, top, $N=24$ ), depressives (b, mid, $N=27$ ) and controls (c, bottom, $N=18$ ). Mean percentages of dipoles/s (transformed into normal distribution) of artifact-free epochs are mapped onto schematic brain (Montreal brain) for 10 areas (prefrontal, frontal, temporal, parietal, and occipital in each hernisphere). Front view (top left), back view (top right), right-hemispheric view (bottom left) and left-hemispheric view: (bottom right). Different dipole densities are illusirated by color shadings, the lowest dipole densities being represented by blue and the highest dipole densities by red color shadings. 
subjects $(p<0.05)$, and the higher delta dipole densities in female schizophrenic than in depressive patients $(p<0.01)$.)

Effects of medication on the pattern of slow wave activity were examined (a) by comparing subgroups receiving different types of medication within each patient group (tricyclic antidepressants, selective serotonine reuptake inhibitors, neuroleptics within the depression group, typical, atypical in the schizophrenic group), and (b) by an ANOVA on subsamples of 18 controls, 11 depressives receiving SSRI and 11 schizophrenics receiving typical neuroleptic. Subgroups did not differ significantly in the patterns of slow wave activity. Posthoc $t$ tests confirmed similar group differences for all areas $(p<0.05)$.

Similar pattern was obtained for theta activity (ANCOVA with age as covariate, GROUP $\times$ AREA, $F(8,256)=4.22, \quad \epsilon=0.56, \quad p<0.01 ; \quad$ GROUP, $F(2,64)=10.4, p<0.001)$. Examining effects of medication by comparing theta dipole densities between subsamples of 18 controls, 11 schizophrenics with typical neuroleptics and 11 depressives with SSRI confirmed the group-specific patterns (GROUP $\times$ AREA, $F(8,148)=2.15, \quad p<0.05 ; \quad$ GROUP, $\quad F(2,37)=4.10$, $p<0.05$; AREA, $F(4,8)=4.42, p<0.01)$. Depressives displayed significantly reduced frontal and prefrontal theta activity relative to the other two groups (posthoc $t$ tests, $p<0.01$ ), schizophrenics significantly higher left-temporal theta activity relative to the other two groups, $p<0.05$ ).

Delta dipole clustering varied with diagnosis-specific symptoms (Fig. 2). Relationships with group-specific characteristic symptoms were evaluated for those areas of significant deviances relative to the control group. In 21 schizophrenic patients, for whom ratings were available, higher left-temporal delta dipole density correlated with higher hallucinations and paranoia scores (combined) of the PANSS-P $(r=0.50, p<0.02)$. For 22 depressives, for whom ratings were available, higher self-ratings of depressive symptoms (BDI scores) varied with less

\section{schizophrenic sample}

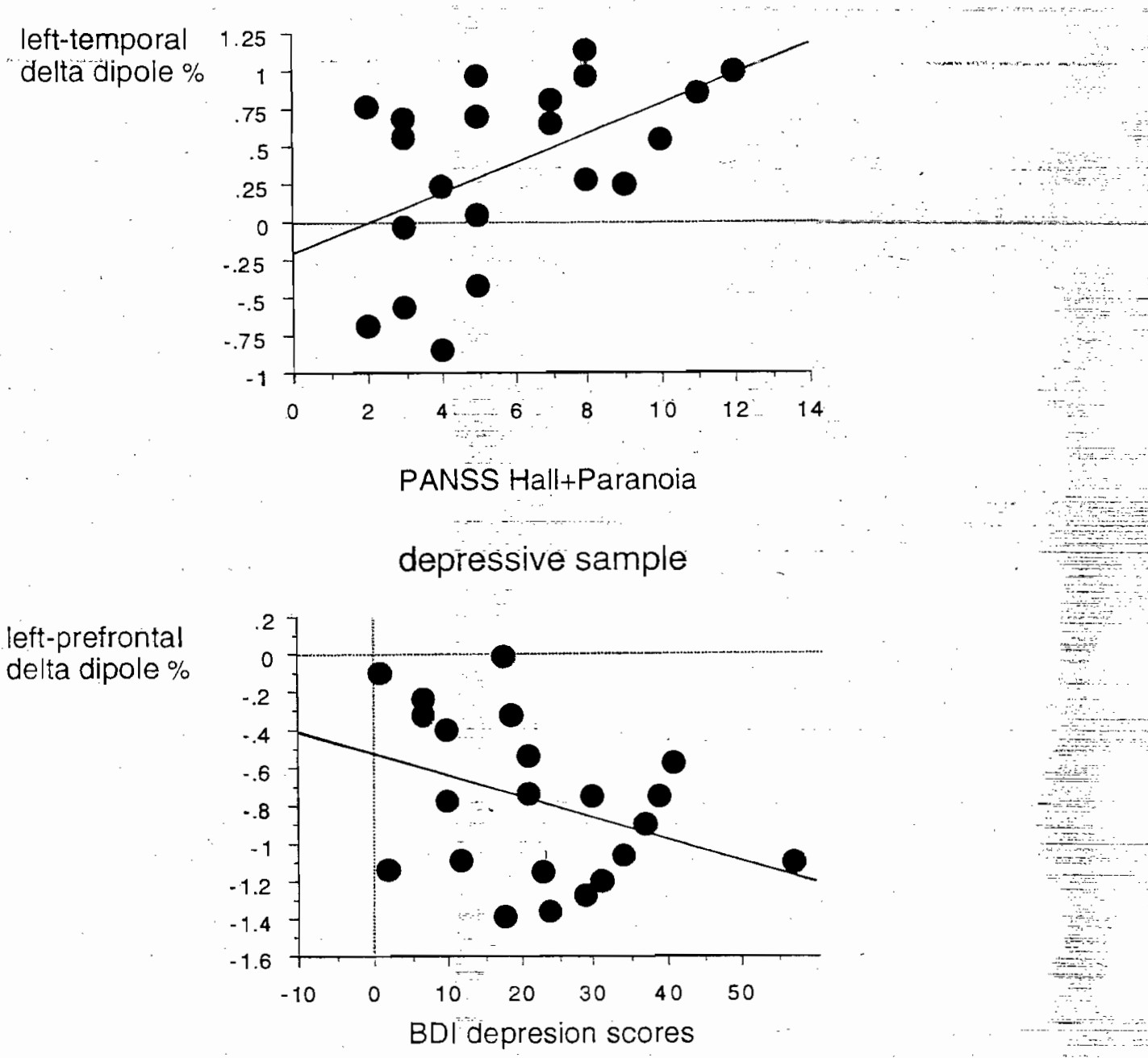

Fig. 2. Single-subject distribution of symptom scores (abscissae, relative to dipole densities (ordinates). Top: distribution of left-temporal dipole density relative to scores on the PANSS hallucination plus paranoia items in 21 schizophrenics. Bottom: distribution of left-prefrontal dipole density relative to BD depression scores in 22 depressives. 
left-prefrontal delta dipole density $(r=-0.66, p<0.005)$ (applying the Holm correction, the latter coefficient remained significant ${ }^{2}$ ).

\section{Discussion}

The present study disclosed regional accentuation of slow wave activity in different diagnostic groups. In schizophrenic patients, the regions of more frequent generators in the delta and theta bands correspond to areas that are related to pathology in other paradigms and on the basis of structural and functional measures (McCarley et al., 1999; Shenton et al., 2001). Moreover, the presently observed relationship of temporal delta activity and auditory ballucinations is in line with results from imaging studies, which found hallucinations to vary with activity in the auditory cortices and the temporal lobes (Tiihonen et al., 1992; Silbersweig et al., 1995). A reduction of frontal and prefrontal slow waves found in the present depressive sample is in line with EEG-results (Brenner et al., 1986; Pozzi et al., 1995). They may also be discussed in the framework of PET-results disclosing hypometabolism in the inferior frontal lobe (Bench-et al.; 1992; Mayberg; 2001) and prefrontal cortex (Baxter et al., 1989), and of fMRI results of less activation of the left lateral prefrontal cortex in response to affective pictorial stimuli (Davidson et al., 2003). The potentially 'dysfunctional' nature of this reduced slow wave activity relationship is supported by effects of electroconvulsive therapy (ECT), which has been reported to result in an increase of EEG- and MEG-delta power, particularly in prefrontal areas and particularly with effective symptomi reduction (Rosen and Silfverskiöld, 1987; Sackeim et al., 1996; Sperling et al., 2000), and by 'normalising' effects of antidepressants on brain activation (Davidson et al., 2003). The 'dysfunctional' nature of focal slow wave abnormality. was also suggested by the relationship to symptomatology in the present groups. Although the statistical significance is too limited to allow explicit conclusions, the few and selective significant correlation coefficients may be considered a clue to a potential relationship between deviant information processing in distinct cortical regions-as indicated by focal slow wave abnormality - and psychopathology_-as indicated by symptom scores. Although EEG findings of augmented slow wave activity in neuropathology (Walter, 1936; Lewine and Orrison, 1995) and localization of sources of neuromagnetic

\footnotetext{
2 When symptom scores were correlated with delta dipole density in all 10 areas, only two coefficients were significant, the correlation of left-temporal delta activity and the combined PANSS hallucinations + paranoia score in schizophrenia, and the negative correlation of left-prefrontal delta activity and the BDI score in depression. Although these coefficients were only marginally significant after correcting for mulriple testing: the fact that all other coefficients were far from significant may be takien as support of the restricted and pointed relationship between the behavioral and the neurophysiological level.
}

slow wave activity in the vicinity of ischemic tissue and neoplasms (Vieth et al., 2000; Gallen et al., 1992, 1993) suggest to relate abnormal slow wave activity to dysfunctional tissue, it is currently not known what distinguishes 'normal' slow wave activity from the one with dysfunctional significance. We proposed that focal slow wave accentuation indicates 'dysfunctional' brain regions also in psychiatric disorders. A neurobiological/neuronal level of abnormal brain functioning, or information processing consequent upon different etiology and prerequisite for different neuropsychological, behavioral abnormalities or symptoms has been integrated in models of psychopathology, for instance in schizophrenia (Andreasen, 1997; Maynard et al., 2001). Abnormal focal slow wave activity may represent this neurobiological level of deviant neuronal network architecture or communication. For affective disorders, a dysfunctional brain circuitry underlying emotion regulation, which involves the prefrontal cortex, amygdala, and anterior cingulate is modeled on the basis of evidence of reduced activation in these areas (overview Davidson et al., 2003). The specific mode of translation of neurophysiological abnormality into focal slow wave deviances (like functional deafferentation in schizophrenia, reduced inhibition in depression) remains to be clatified for the different diagnostic groups. Nevertheless, the pattern of focal slow wave activity may be considered an indication of abnormality on this neurobiological level of neuronal network function and communication.

Finally, the effect of medication varied in the present sample, recruited from a State Hospital with predominantly chronic, medicated patients. Although diagnosis-specific slow wave patterns were roughly similar for the original sample and a subsample of patients with neuroleptic or antidepressant monotherapy, the latter comparison suggested that typical neuroleptics may attenuate lefttemporal slow wave activity (reducing differences between groups). It is certainly preferable to substantiate this result with larger groups per type of medication. However, effect of medication is difficult to specify for several reasons: a slowing of EEG frequencies has been reported as a consequence of neuroleptic medication (Koshino et al., 1993; Malow et al., 1994), but also of 'normalizing' effects (Saletu et al., 1990, 1994; Canive et al., 1996, 1998). In depressive patients, Saletu et al. (1980) found SSRI and imipramine to increase slow wave activity, while Sperling et al. (2000) did not report an increase in the dipole density in the slow activity range in a patient group treated with tricyclic antidepressants. 'Normalisation' of the reduced activation in the left insular and anterior cingulate together with symptom change was reported consequently upon antidepressant treatment by Davidson et al. (2003). Furthermore, the amount of medication varies with the severity of the illness. It seems likely that more impaired patients with higher symptom scores received higher doses of medication. Finally, medication is assumed to affect the dopaminergic and serotonergic systems, with their 
widespread cortical and subcortical innervations. It is not well understood to what extent neuroleptic and antidepressive medication might affect the two cerebral hemispheres differentially, and thus might influence the hemispheric distribution of brain wave activity.

The present results call for further investigation as they strongly suggest that the pattern of focal slow wave activity is differentially related to psychiatric diagnoses depending on the particular symptom profiles. Further studies might reveal to what extent abnormal slow wave mapping, obtained in a standardized, non-demanding setting, may serve as an objective means to assist diagnostic purposes.

\section{Acknowledgements}

Research was supported by the Deutsche Forschungsgemeinschaft and the Volkswagen-Stiftung. We thank Drs. H. Watzl, K. Pröpster, P. Rössner, and M. Schlie for accomplishing the diagnostics and clinical status of the patients.

\section{References}

Allen JJ, Iacono WG; Depue RA, Arbisi P. Regional electroencephalographic asymmetries in bipolar seasonal affective disorder before and after exposure to bright light. Biol Psychiatry 1993;33:642-6.

Amzica F, Steriade M. The K-complex: its slow $(<1 \mathrm{~Hz})$ rhythmicity and relation to delta waves. Neurology 1997;49:952-9.

Andreasen N. The evolving concept of schizophrenia: from Kraelepin to the present and future. Schizophr Res 1997;28:105-9.

Baxter LR, Schwartz JM, Phelps ME, Mazziotta JC, Guze BH, Selin CE, et al. Reduction of prefrontal cortex glucose metabolism common to three types of depression. Arch Gen Psychiaury 1989;46:243-50.

Begic D, Hotujac L, Jokic-Begic N. Quantitative EEG in 'positive' and 'negative' schizophrenia. Acta Psychiatrica Scandinavia 2000;101: 307-11.

Begic.D, Hotujac L, Jokic-Begic N. Electroencephalographic comparison of veterans with combat-related post-traumatic stress disorder and healthy subjects. Int J Psychophysiology 2001;40:167-72.

Bench CI, Friston KJ, Brown RG, Lynette CS, Frackowiak RSJ, Dolan RJ. The anatomy of melancholia-focal abnormalities of cerebral blood flow in major depression. Psychol Med 1992;22:607-15.

Berendse HW, Verbunt JP, Scheltens P, van Dijk BW, Jonkman EJ. Magnetoencephalographic analysis of cortical activity in Alzheimer's disease: a pilot study. Clinical Neurophysiol 2000;111:604-12.

Bogerts B. The temporolimbic system theory of positive schizophrenic symptoms. Schizophr Bull 1997;23:423-35.

Brenner RP, Ulrich RF, Spiker DG, Sclabassi RJ, Reynolds III CF, Marin RS, et al. Computerized EEG spectral analysis in elderly nomal, demented and depressed subjects. Electroenceph clin Neurophysiol 1986;64:483-92.

Buchan RJ, Nagata K, Yokoyama E, Langman H, Yuga H, Hirata $Y$, et al. Regional correlations between the EEG and oxygen metabolism in dementia of Alzheimer's tvpe. Clin Neurophysiol 1997;103:409-17.

Canive TM, Lewine JD, Edgar JC, Davis JT, Tortes F, Roberts B, et al. Magnetoencephalographic assessment of spontaneous brain activity in -schizophrenia. Psychopharmacol Bull 1996:32:741-50.

Canive TM, Lewine JD, Edgar JC, Davis JT. Miller GA, Tones F, et al Spontaneous brain magnetic activity in schizopbrenic patients treated with aripiprazole. Psychopharmacol Bull 1998:34:101-5.
Clementz BA, Sponheim SR, Iacono WG, Beiser M. Resting EEG in firstepisode schizophrenia patients, bipolar psychosis patients, and their first-degree relatives. Psychophysiology 1994;31:486-94

Dahabra S, Ashton CH, Bahrainian M, Britton PG, Ferrier IN, McAllister VA, et al. Structural and functional abnormalities in elderly patients clinically recovered from early- and late-onset depression. Biol Psychiatry 1998;44:34-46.

Davidson R, Irwin W, Anderle MJ, Kalin NH. The neural substrates of affective processing in depressed patients treated with Venlafaxine. Am J Psychiatry 2003;160:64-75.

Debener S, Beauducel A, Nessler D, Brocke B, Heilemann H, Kayser J. Is resting anterior EEG alpha asymmetry a trait marker for depression? Neuropsychobiology 2000;41:31-7

De Jongh A, de Munck JC, Baayen JC, Jonkman ET, Heethaar RM; van Dijk BW. The localization of spontaneous brain activity: first results in patients with cerebral tumors. Clin Neurophysiol 2001; $112: 378-85$.

DeJongh A, Bayen JC, deMunck JC, Puligheddu M, Stam CJ. Locations of sharp wave and slow wave generators in patients with brain tumors. In: Nowak, et al., editors. BIOMAG 2002. Proceedings of the 13 th International Conference on Biomagnetism; 2002. p. 161-3.

Dierks T, Jelic V, Pascual-Marqui RD, Wahlund L, Julin P, Linden DE, et al. Spatial pattern of cerebral glucose metabolism (PET) correlates with localization of intracerebral EEG-generators in Alzheimer's disease. Clin Neurophysiol 2000;111:1817-24.

Elbert T. Neuromagntism. In: Andrä W, Nowak H, editors. Magnetism in medicine. New York, NY: J. Wiley and Sons; 1998. p. 190-262.

Elbert T, Lutzenberger W, Rockstroh B, Berg P, Cohen R. Physical aspects of the EEG in schizophrenics. Biol Psychiatry 1992;32: $595-606$.

Fehr T, Kissler J, Moratti S, Wienbruch C, Rockstroh B, Elbert T. Source distribution of neuromagnetic focal slow waves and MEG-delta activity in schizophrenic patients. Biol Psycliatry 2001;50:108-16.

Fehr T, Kissler J, Wienbruch C, Moratti S, Elbert T, Watzl H, Rockstroh B. Source distribution of neuromagnetic slow-wave activity in schizophrenic patients-effects of activation. Schizophr Res 2003;63: $63-70$.

Fernandez-Bouzas A, Harmony T, Bosch J, Aubert E, Fernandez T, Valdes $P$, et al. Sources of abnormal EEG activity in the presence of brain lesions. Clin Electroencephalogr 1999;30:46-52.

Franciotti R, Iacono D, Della Penna S, Di Rollo A, Pizella V, Torquati K Romani G, Onofnij MA. MEG study of the cerebral rhythm in patients with cognitive deterioration: A preliminary study. In: Nowak, et al. editors. BIOMAG 2002. Proceedings of the 13th International Conference on Biomagnetism; 2002. p. 167-9.

Gallen CC, Schwartz BJ, Pantev C, Hampson S, Sobel D, Hirschkoff EC et al. Detection and localization of delta frequency activity in human strokes. In: Hoke M, Erné SN, Okada YC, Romani GL, editors. Biomagnetism: clinical aspects. Amsterdam: Excerpta Medica; 1992 p 301-5.

Gallen CC, Sobel D, Wảltz T, Aung M, Copeland B, Schwartz BJ, et al Noninvasive presurgical neuromagnetic mapping of somatosensory. cortex. Neurosurgery 1993;33:260-8.

Gloor P, Ball G, Schaul N. Brain lesions that produce delta waves in the EEG. Neurology 1977;27:326-33.

Harris AW, Williams L, Gordon E, Bahramali H, Slewa-Younan S Different psychopathological models and quantified EEG in schizophrenia. Psychol Med 1999;29:1175-81.

Harris AW, Bahramali H, Slewa-Younan S, Gordon E, Williams L, Li WM The topography of quantified electroencephalography in three syndromes of schizophreria. Int J Neurosci 2001:107:265-78.

Heikman P, Salmehin R, Matela JP, Hari R, Katila H, Kuoppasaini K Relation between frontal $3-7 \mathrm{~Hz}$ MEG activity and the efficacy of ECT in major depression. J ECT 2001:17(2):136-40.

Henriques JB, Davidson RJ. Left frontal hypoactivation in depression. J Abnorm Psychol 1991;100:535-45. 
Holm S. A simple sequentially rejective multiple test procedure. Scand J Stat 1979:6:65-70.

Jones EG. Cortical development and thalamic pathology in schizophrenia. Schizophr Bull 1997;23:483-501.

Kay SR, Fiszbein A, Opler LA. The positive and negative syndrome scale (PANSS) for schizophrenia. Schizophr Bull 1987;13:261-75.

Knott VJ, Lapierre YD. Computerized EEG correlates of depression and antidepressant treatment. Prog Neuropsychopharmacol 1987;11: $213-21$.

Knott V, Mahoney C, Kennedy S, Evans K. Pre-treatment EEG and it's relationship to depression severity and paroxetine treatment outcome. Pharmacopsychiatry 2000;33(6):201-5.

Koshino Y, Murata I, Morata T, Omori M, Hamada T, Myagoshi M, et al. Frontal intermittent delta activity in schizophrenic patients receiving antipsychotic drugs. Clin Electroencephalogr 1993:24: $13-18$.

Landolt HP, Gillin JC. Different effects of phenelzine treatment on EEG topography in waking and sleep depressed patients. Neuropsychophatmacology 2002;27:462-9.

Lewine ID, Orrison WW. Clinical electroencephalography and eventrelated potentials. In: Orrison WW, Lewine JD, Sanders JA, Hartshome $\mathrm{MF}$, editors. Functional brain imaging. St Louis, MO: Mosby-Year Book, Inc.; 1995. p. 327-68

Lewine ID, Canive J, Edgar C, Davis J. Neuromagnetic correlates of auditory hallucinations in schizophrenia: preliminary findings (manuscript 2002), submitted for publication.

LTinäsR, Ribary U, Yeannerod D, Kronberg E, Mitra $\bar{P} P$. Tha a a mocortical dy'shythmia: A neurological and neuropsychiatric syndrome characterized by magnetoencephalography. Proc Natl Acad Sci U.S.A. 1999; 96:15222-7.

Luber B, Nobler MS, Moeller JR, Katzmann GP, Prudie J, Devanand DP, et al. Quantitative EEG during seizures induced by electroconvulsive therapy: relations to treatment modality and clinical features. II. Topographic analyses. J ECT 2000;16:229-43.

Malow BA, Reese KB, Sato S, Bogard PJ, Malhotra AK, Su TP, et al. Spectrum of EEG abnormalities during clozapine treatment. Clin Neurophysiol 1994;91:205-11.

Mayberg HS. The depressed brain image. 154th Annual Meeting of the American Psychiatric Association, New Orleans; 2001.

Maynard TM, Sikich L, Lieberman IA, LaMantia AS. Neural development, cell-cell signaling, and the "two-hit" hypothesis of schizophrenia. Schizophr Bull 2001;27:457-76.

McCarley RW, Wible CG, Frumin M, Hirayasu Y, Levitt JJ, Fischer IA, et al. MRI anatomy of schizophrenia. Biol Psychiatry 1999;45: 1099-119.

Möller M, Kober H, Ganslandt O, Begerow A, Vieth J, Fahlbusch R. Abrormal neuronal activity in brain tumor patients localized by magnetoencephalography. In: Nenonen J, et al., editors. Biomag 2000. HUT 2002. p. $428-30$

Niedermeyer E, Löpes da Silva F. Electroencephalography: basic principles, clinical applications and related fields. Baltimore, MD: Urban \& Schwarzenberg; 1987.

Nystrom C, Matousek M, Hallstrom T. Relationships between EEG and clinical characteristics in major depressive disorder. Acta Psychiatr Scand 1986:73:390-4.

Oldfield RC. The assessment and analysis of handedness: the Edinburgh inventory. Neuropsychologia 1971;9:157-200.

Pascual-Marqui R, Lehmann D, König T, Kochi K, Merlo MC, Hell D, Koulkou $M$. Low resolution brain electromagnetic tomography -(LORETA) functional imaging in acute, neuroleptic-naive, firstepisode, productive schizophrenia. Psychiatry Research 1999;90: $169-79$.

Poliock $V^{\prime} E$, Schneider LS. Topographic quantitative EEG in elderly subjects with major depression. Psychophysiology 1990;27:438-44.

Pozzi D. Golimstock A, Petracchi M, Garcia H, Starkstein S. Quantified electroencephalographic changes in depressed patients with and uithout dementia. Biol Psychiatry 1995:38:677-83.
Rosen I, Silfverskiöld P. Quantification of EEG changes following electroconvulsive therapy in depression. Eur Arch Psycbiatry Neurol Sci 1987:236:209-13.

Sackeim HA, Luber B, Katzman GP, Moeller JR, Prudic J, Devanand DP, et al. The effects of electroconvulsive therapy on quantitative electroencephalograms. Relationship to clinical outcome. Arch Gen Psychiatry 1996;53:814-24.

Saletu B, Grunberger J, Rajna P, Karobath M. Clovoxamine and fluvoxamine-2 biogenic amine reuptake infibiting antidepressants: quantitative EEG, psychometric and pharmacokinetic studies in man. J Neural Transm 1980;49:63-86.

Saletu B, Kuefferle B, Anderer P, Gruenberger J, Steiberger K. EEG-brain mapping in schizophrenics with predominantly positive and negative symptoms: comparative studies with remoxipride/haloperidol. Eur Neuropsychopharmacol 1990;1:27-36.

Saletu B, Kuefferle B, Gruenberger J, Foldes P, Topitz A, Anderer P. Clincal EEG mapping and psychometric studies in negative schizophrenia: comparative trials with amisulpride and fiuohenazine. Neuropsychobiology 1994;29:125-35.

Schulz C, Mavrogiorgou P, Schroter A, Heger1 U, Juckel G. Lithiun. induced EEG changes in patients with affective disorders. Neuropsychobiology 2000;42(1):33-7.

Shenton MF, Dickey CC, Frumin M, McCarley RW. A review of MRI findings in schizophrenia. Schizophr Res 2001;15:1-52.

Silbersweig DA, Stern E, Frith C, Cahill C, Holmes A, Grootonk S, et al. A functional neuroanatomy of hallucinartiơnis in schirzööphrenia." Nature 1995:378:176-9.

Sperling W, Martus P, Alschbach M. Evaluation of neuronal effects of electroconvulsive therapy by magnetoencephalography (MEG). Prog Neuropsychopharmacol 2000:24:1339-54

Sperling W, Martus P, Kober H. Bleich S, Kornhuber J. Spontaneous, slow and fast magnetoencephalographic activity in patients with schizophrenia. Schizophr Res 2002;58:189-99.

Sponheim SR, Clementz BA, Iacono WG, Beiser M. Clinical and biological concomitans of resting state EEG power abnormalities in schizophrenia. Biol Psychiatry 2000;48:1088-97.

Steriade M. Synchronized activities of coupled oscillators in the cerebral cortex and thalamus at different levels of vigilance. Cereb Cortex 1997; 7:583-604.

Stevens JR, Bigelow L, Denney D, Lipkin J, Livermore AH Jr, Rauscher F, Wyatt RI, Telemetered EEG-EOG during psychotic behaviors of schizophrenia. Arch Gen Psychiatry 1979;36:251-62.

Tïhonen J, Hari R, Naukkarinen H, Rimon R, Jousmaki V, Kajola M. Modified activity of the human auditory cortex during auditory hallucinations. Am J Psychiatry 1992;149:255-7.

Tanaka A, Kimura M, Yoshinaga S, Tomonaga M, Mizoguchi $T$ Quantitative electroencephalographic correlates of cerebral blood flow in patients with chronic subdural hematomas. Surg Neurol 1998; 50:235-40

Teicher MH, Andersen SL, Polcari A, Anderson CM, Navalta CP. Developmental neurobiology of childhood stress and trauma. Psychiatr Clinic North Am 2002:25:397-426.

Vieth J, Kober H, Gummich P. Sources of spontaneous slow waves associated with brain Jesions, localized by using the MEG. Brain Topography 1996;8:215-21.

Vieth J, Kober H, Kamada K, Ganslandt O. Normal and abnormal MEG activity in border zones of brain lesions. In: Koga $\mathrm{Y}$, et al., editors. Brain Topography Today. Amsterdam: Elsevier; 1998. p. 39-46.

Vieth JB, Kober H, Gansiandt O, Möller M, Kamada K. The clinical use of MEG activity associated with brain lesions. Proceedings of the 12th International Conierence on Biomagnetism, Helsinki; 2000.

Visser SL, Van Tilburg W, Hoojer C, Jonker C, De Rijke W. Visual evoked potentials (VEPs) in senile dementia (Alzheimer type) and in non-organic behavioural disorders in the elderly: comparison with EEG parameters. Electroenceph clin Neurophysiol 1985;60:115-21. 
Volf NV, Passynkova NR. EEG mapping in seasonal affective disorder. J Affect Disord 2002;72:61-9.

Walter $G$. The location of cerebral tumors by electroencephalography. Lancet 1936;8:305-8.

Wing JK, Cooper JE, Sartorius N. Die Erfassung und Klassifikation psychiatrischer Symptome. Weinheim: Beltz; 1982.
Winterer G, Herrmann WM. Über das Elehtroenzephalogramm in der Psychiatrie: Eine kritisehe Bewertung. Z Elektroenzephalogr, Elektromyogr Verwandte Geb 1995:26:19-37.

Wittchen HU, Wunderlich U, Gruschewitz S, Zaudig M. Strukturierteś Klinisches Interview für DSM-IV (SKID). Hogrefe: Göttingen; 1997. 